\title{
RECENT TSUNAMIS OBSERVED BY GPS BUOYS OFF THE PACIFIC COAST OF JAPAN
}

\author{
Hiroyasu Kawai ${ }^{1}$, Makoto Satoh ${ }^{2}$, Koji Kawaguchi ${ }^{1}$ and Katsumi Seki ${ }^{1}$
}

\begin{abstract}
This paper describes the overview of the 2010 Chilean and 2011 Tohoku Foreshock and Main Shock Tsunami profiles, which were acquired by GPS-mounted buoys at a spot of 100-400 $\mathrm{m}$ in water depth off the Pacific coast of Japan. In the case of the first crest on the 2011 Tohoku Main Shock Tsunami profile acquired off Kamaishi Port, the water level rose relatively slowly and quickly at the primary and subsequent parts, respectively, and consequently exceeded $6 \mathrm{~m}$.
\end{abstract}

Keywords: GPS buoy; 2010 Chilean tsunami; 2011 Tohoku tsunami; wave crest; shallow-water transformation

\section{INTRODUCTION}

The Ports and Harbours Bureau, Ministry of Land, Infrastructure, Transport and Tourism, Japan, and its associated organizations, including the Port and Airport Research Institute (hereinafter, PARI), have been conducting wave and tide observations around Japan, central data processing, and data dissemination, through the Nationwide Ocean Wave Information Network for Ports and Harbours (hereinafter, NOWPHAS) (Nagai et al., 2008). The data accumulated through the coastal wave and tide gauges since 1970 include not only high-wave events, but also the tsunami triggered by the 1983 Nihonkai-Chubu Earthquake, the 1993 Hokkaido-Nansei-oki Earthquake, the 2003 Tokachi-oki Earthquake, the 2004 Tokaido-oki Earthquake, the 2005 Miyagi-ken-oki Earthquake, and the 2006 Kuril Islands Earthquake (Tanimoto et al., 1983; Takayama et al., 1994; Nagai et al., 2004, 2005a, 2006b; Shimizu et al., 2007). Recently the operation of GPS buoys, that are moored at a spot of 100$400 \mathrm{~m}$ in water depth and 10-20 km from the coast line and measure the water level every second using real-time kinematic GPS technology, was started on NOWPHAS, after a research team successfully used an experimental standalone GPS buoy to acquire data on the tsunami triggered by the 2001 Peru Earthquake, the 2003 Tokachi-oki Earthquake, and the 2004 Tokaido-oki Earthquake (Kato et al., 2005; Nagai et al., 2005b, 2006a, 2007). The nationwide network of the GPS buoys as well as the coastal wave and tide gauges on NOWPHAS was successful to acquire the 2010 Chilean and 2011 Tohoku Foreshock and Main Shock Tsunami profiles (Kawai et al., 2011, 2012; PARI, 2011). This paper introduces the GPS buoy system on NOWPHAS and then describes the overview of these three tsunami profiles.

\section{GPS BUOY SYSTEM ON NOWPHAS}

\section{Data Acquirement}

Fig. 1 shows three categories of the NOWPHAS equipment for tsunami detection; they are a coastal tide gauge (hereinafter, abbreviated as TG in figures), coastal wave gauge (WG), and GPS buoy
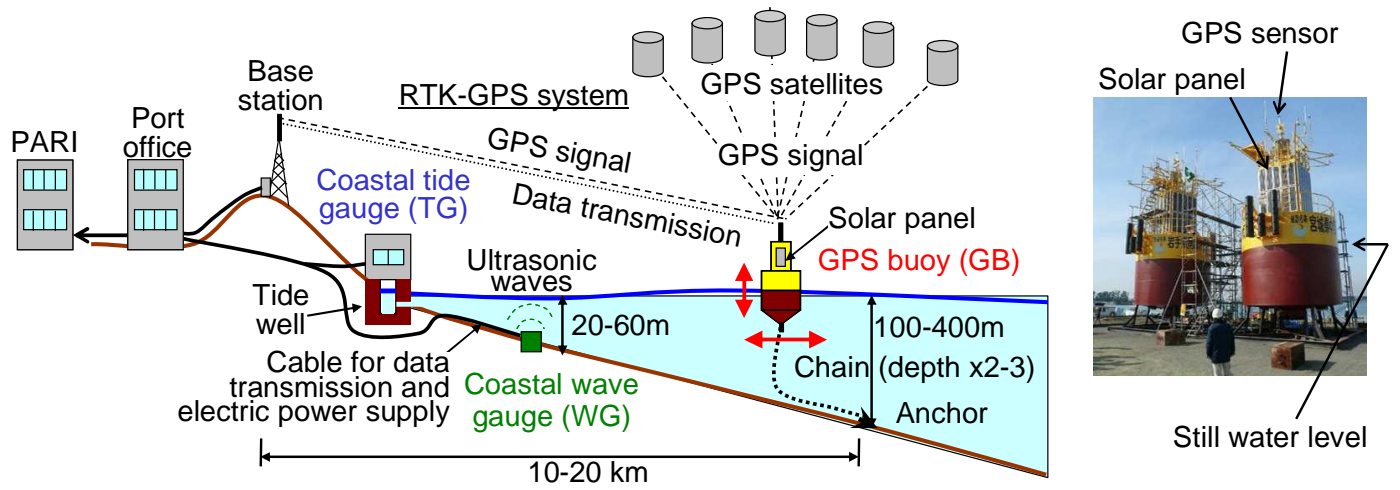

Figure 1. NOWPHAS equipment for tsunami detection

Still water level

\footnotetext{
${ }^{1}$ Marine Information Field, Port and Airport Research Institute, 3-1-1, Nagase, Yokosuka, Kanagawa, 239-0826, Japan

2 Tohoku Regional Development Bureau, Ministry of Land, Infrastructure, Transport and Tourism, 1-1-20, Kakyoin, Aoba-ku, Sendai, Miyagi, 980-0013, Japan; Formerly a member of Marine Information Field, Port and Airport Research Institute
} 
(GB), in the order of increasing the distance from the coastal line. The coastal tide gauge is generally located on a wharf or a seawall and measures the water level in a tide well, which is connected to the sea with an inlet pipe. The coastal wave gauge is often installed on a 20-60 m deep seabed and measures the water surface elevation every $0.5 \mathrm{~s}$ using ultrasonic waves. The tide level can be estimated by smoothing the time series of the water surface elevation with a digital filter. The GPS buoy is moored by a steel chain at a spot of 100-400 $\mathrm{m}$ in water depth and 10-20 km from the coastal line.

Acceleration buoys, which measure the acceleration and tilting angle of the buoy and then calculate the vertical motion, are very popular in deep-water areas where the installation of a seabed wave gauge is difficult. These buoys, however, have disadvantages in extracting tide levels owing to the feeble accelerations. In contrast, the GPS buoy system measures the buoy altitude above the Earth ellipsoid WGS84 every second using the RTK-GPS instruments on the buoy and at the base station, as illustrated in Fig. 1. Following are the four GPS positioning conditions, in the order of decreasing accuracy; the fix solution, float solution, DGPS solution, and unsolved. According to a positioning experiment between two immovable points on land, the root-mean-squares of the errors in vertical positioning is only a few centimeters in the case of the fix solution for a distance of $20 \mathrm{~km}$. The positioning condition is affected by several factors, such as the GPS satellite number and geometry and the ionosphere condition above the buoy. The positioning condition was stable during the tsunami events; for instance, the rate of the fix solution reached $98 \%$ and $99 \%$ for 2 and 9 GPS buoys, respectively, while the 2011 Chilean tsunami hit the Japanese coast.

The GPS buoy system relies on an approximation that the height from the water surface to the GPS receiver on the top of the buoy is constant, but this height actually changes owing to the tilting of the buoy. The system, therefore, measures the height above the Earth ellipsoid and the tilting angle simultaneously, and then, it estimates the height as if the buoy was standing vertically upright.

\section{Data Processing and Dissemination}

The tidal level at the GPS buoy site is estimated from the time series of the buoy altitude corrected with the tilting angle, by using a $120 \mathrm{~s}$ long rectangular filter and the Hamming window (Shimizu et al., 2006a, 2006b). This calculation uses the buoy altitude data in the fix solution only. The root-meansquares of the errors in the tidal level, therefore, becomes much lesser than that in the buoy altitude data for each second.

The tide anomaly is calculated by subtracting the astronomical tide level from the observed tide level. The astronomical tide level can be calculated using the known tide constituents. Such a procedure is adopted in a real-time processing work on NOWPHAS. Fig. 2 shows an example of the acquired and processed data on the day when the 2011 Tohoku Main Shock occurred.

The processed data are transmitted to Japan Meteorological Agency (hereinafter, JMA), that is

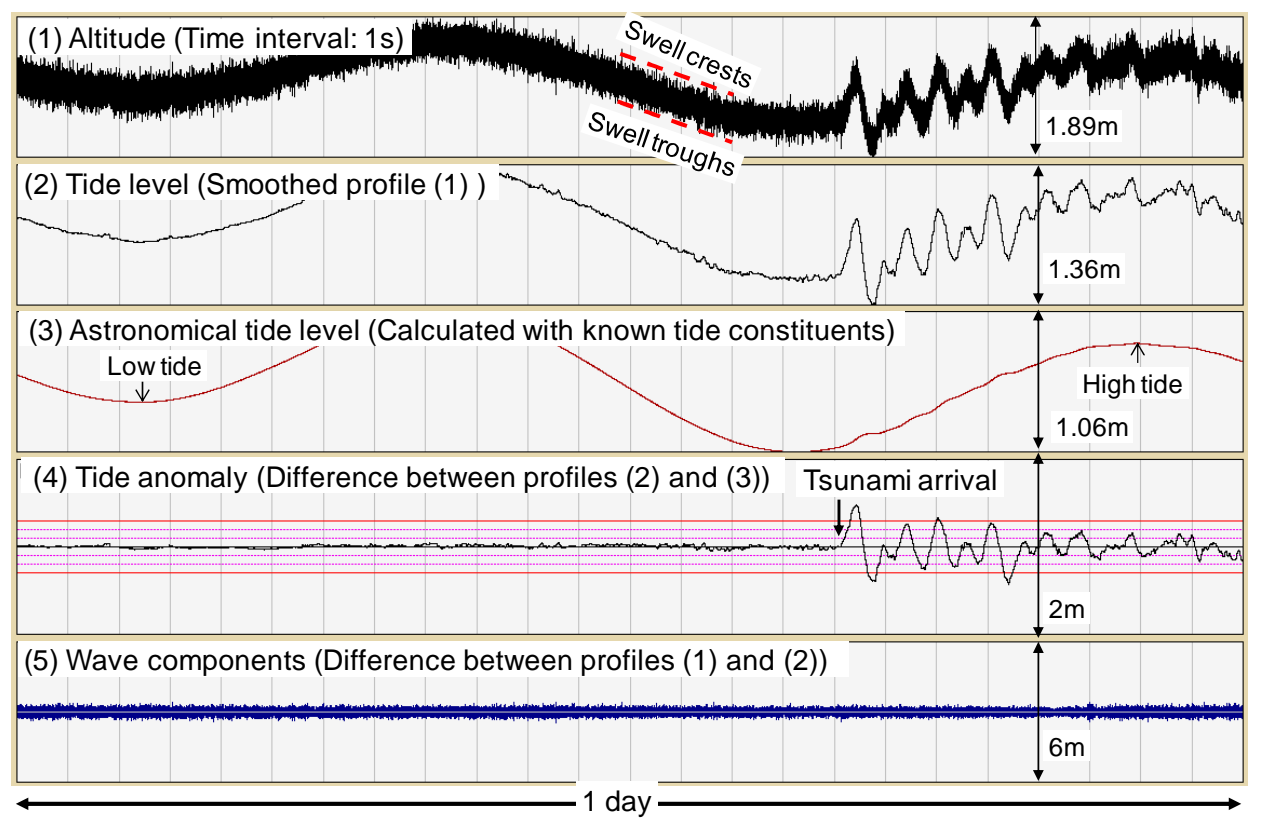

Figure 2. Example of time series of buoy altitude, tide level, astronomical tide level, tide anomaly, and wave components 
responsible for tsunami detection and warning in Japan, on line second by second and are available for the public on the Real-time NOWPHAS Web (http://www.mlit.go.jp/kowan/nowphas/index_eng. html). Fig. 3 shows the 2011 Tohoku Main Shock Tsunami profile acquired at the GPS buoy off Kamaishi Port on the Tohoku region coast. The tsunami profile was unfortunately broken only 3 min after the first tsunami crest appeared, owing to some problems in data communication between the land station and PARI; however, JMA could find the quick increase in the tide anomaly to update his primary prediction of the coastal tsunami height to a higher level. It was confirmed that the first crest was highest during the tsunami event, 10 days after the tsunami event, when the entire data were picked up from the base station and were post-processed at PARI. In contrast, the continuous profiles of the 2010 Chilean and 2011 Tohoku Foreshock Tsunamis were displayed on the website.

\section{Location of GPS Buoys Presented in This Paper}

This study collected the water surface elevation data, which were acquired by the NOWPHAS equipment during three tsunami events; they are the 2010 Chilean and 2011 Tohoku Foreshock and Main Shock Tsunamis. Fig. 4 shows the layout of the GPS buoys and coastal wave gauges on NOWPHAS. Most of the ports have a coastal wave gauge on a seabed off a breakwater and a tide gauge on a wharf or a seawall. Among 12 GPS buoys indicated in the figure, site GB815 was in a primary test

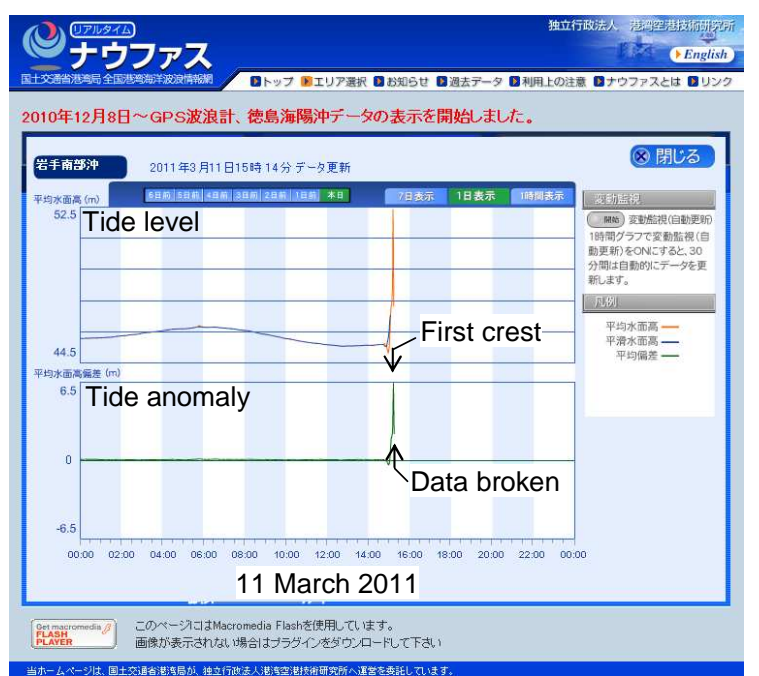

Figure 3. Tsunami profile displayed on Real-time NOWPHAS Web
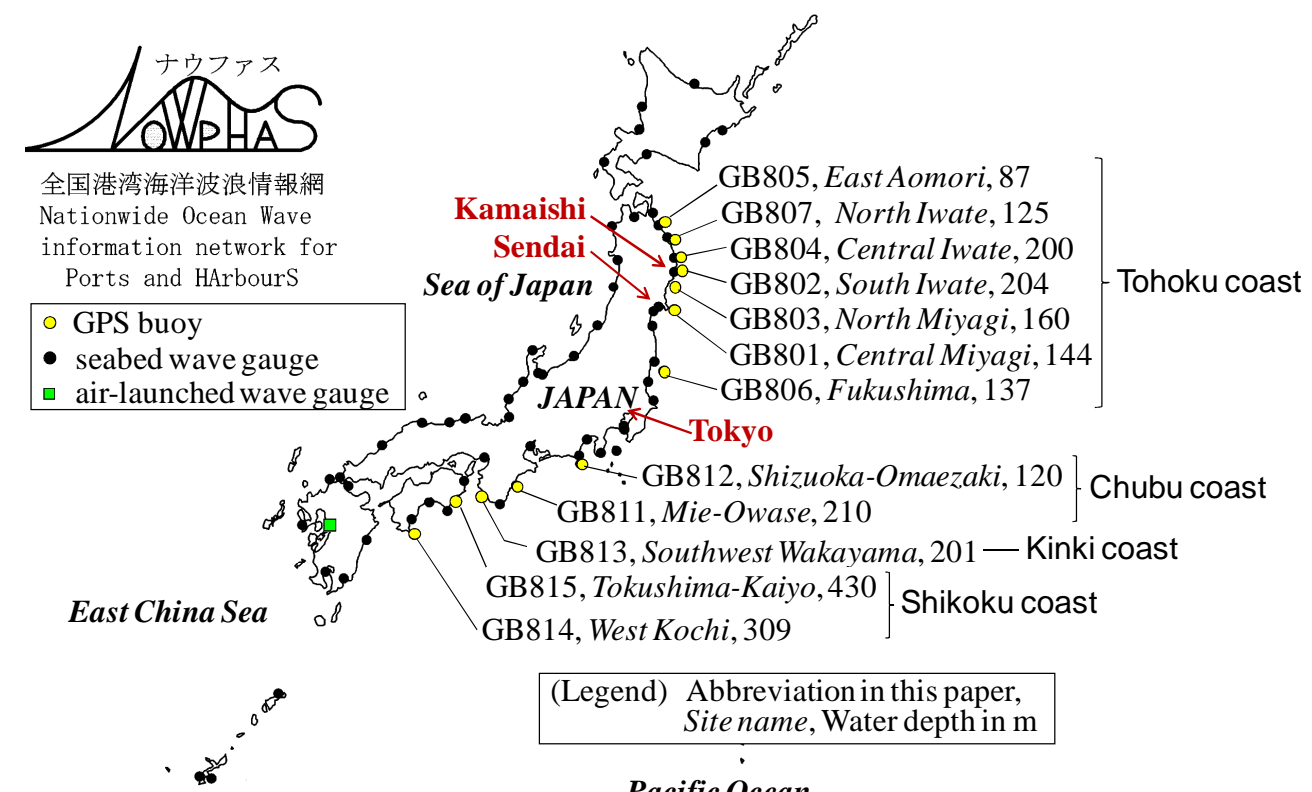

(Legend) Abbreviation in this paper,
Site name, Water depth in $\mathrm{m}$

Pacific Ocean

Figure 4. Layout of GPS buoys and coastal wave gauges on NOWPHAS 
phase when the 2010 Chilean Tsunami hit. The sites GB807 and 804 were undergoing repairs when the 2011 Tohoku Foreshock and Main Shock Tsunami hit. The 2010 Chilean and 2011 Tohoku Foreshock Tsunami did not affect any equipment on the Tohoku region coast, while the 2011 Tohoku Main Shock Tsunami broke most of the coastal wave and tide gauges on the coast.

\section{THE 2010 CHILEAN TSUNAMI}

\section{Earthquake and Wave Condition}

According to JMA's analysis, a massive earthquake $\left(M_{w}=8.8\right)$ occurred in central Chile at 15:34 h, February 27, 2010, Japanese Standard Time (GMT + 9 h). Its tsunami traveled across the Pacific Ocean and reached the Japanese coast nearly one day after the earthquake occurred. It was the first event worldwide that an operational GPS buoy network observed a distinct tsunami profile. On February 28 , the day that the tsunami reached Japan; low-pressure systems were affecting the wind wave and swell conditions around Japan. The significant wave height and period were around $2 \mathrm{~m}$ and $10 \mathrm{~s}$, respectively, at GPS buoy GB802 off Kamaishi Port; further, they were around $1 \mathrm{~m}$ and $7 \mathrm{~s}$, respectively, at the coastal wave gauge near the port entrance.

\section{Tsunami Profile and Frequency Spectrum at GPS buoy sites}

Fig. 5 shows the time series of the tide anomaly acquired by the GPS buoys. The tide anomaly could be extracted from the time series of the tide level by the operational method; subtracting the astronomical tide level that was calculated with the known tide constituents. This paper, however, presents the tide anomaly, which was recalculated using a digital filter with a cutoff period of 209 min, which is the standard used by JMA. Such a digital filter is inconvenient use in real-time tsunami detection because it needs tide level data over a long period; however, this filter is useful for performing detailed analysis of the tide anomaly when the gap between the observed tide level under normal conditions and the calculated astronomical tide level is critical for estimating small tsunami amplitudes of a few tens of centimeters or less.

There was a feeble oscillation on the tide anomaly profile before the tsunami reached. The major causes of the oscillation may be errors in GPS positioning and changes in the tension in mooring chains. The tsunami arrived at GPS buoys GB805, GB807, GB804, GB802, GB803, GB801, and GB806 off the Tohoku region coast after 14:00 h on February 28; and it arrived at others GB812, G811, GB813, and GB814 off the Chubu to Shikoku region coast around 15:00 h. The GPS buoys off the Tohoku region coast were located at $38-65 \mathrm{~km}$ intervals. A match for the first crest at these GPS buoys can be found easily, while but not for the second and subsequent crests. The crest interval is around $60 \mathrm{~min}$ at all the GPS buoys except for GB806 in which case the interval is around $90 \mathrm{~min}$. The black triangle in each site indicates the highest crest between 14:00 h on February 28 and 03:00 h on March 01. The highest crest with a height of 0.1-0.3 m appeared between 15:00 and 19:00 h on February 28 as the first

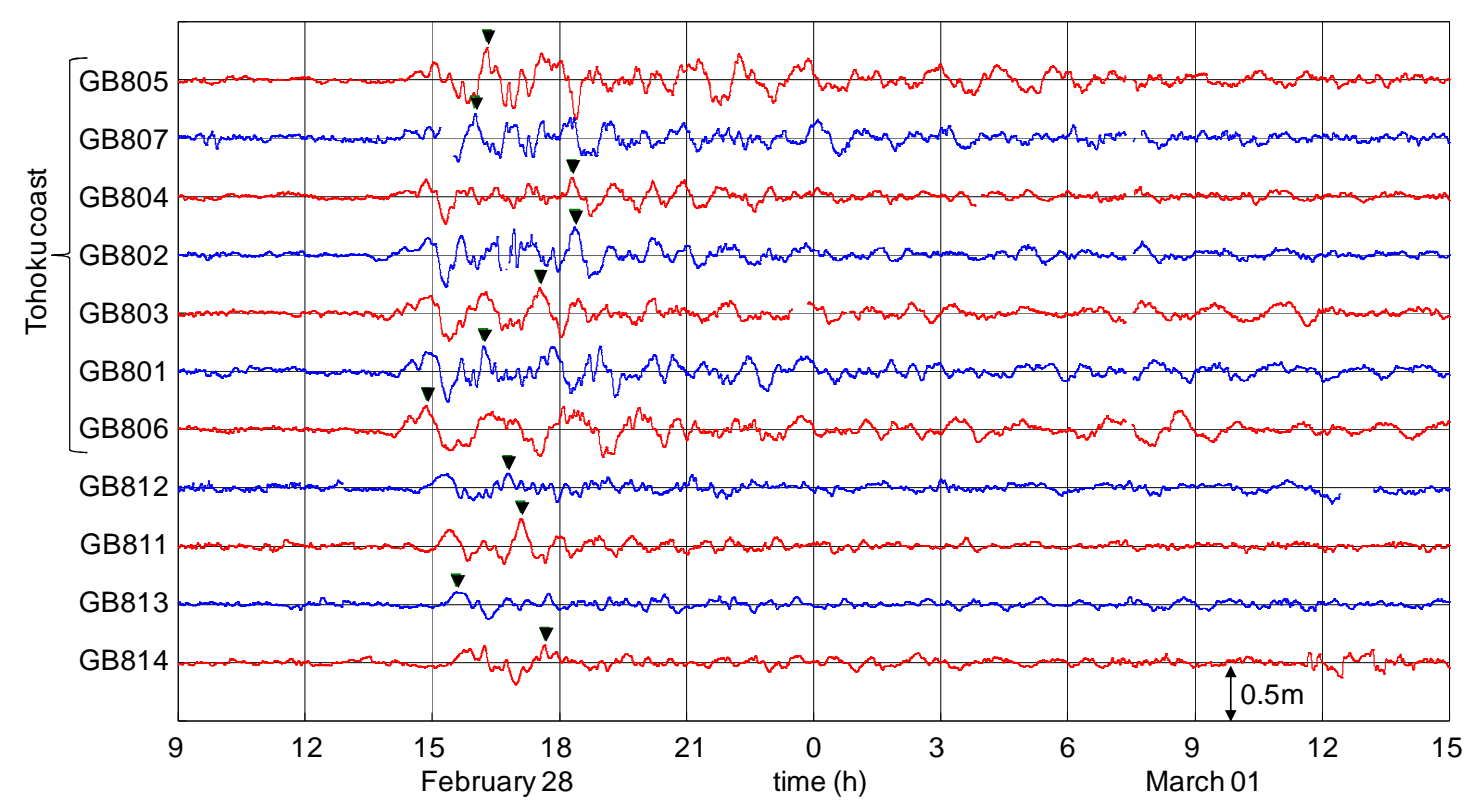

Figure 5. The 2010 Chilean Tsunami profile acquired by GPS buoys 
crest at GB806 and GB813 and appeared as the second or subsequent crest at the other buoys. GPS buoy GB805 recorded the maximum crest height among all the GPS buoys. One of the reasons may be that the GB805 site has the shallowest water depth among all the GPS buoys. It took more than $24 \mathrm{~h}$ for the tide anomaly to approach zero.

Fig. 6 compares the frequency spectra of the tide anomaly at all the GPS buoys, during approximately $5.7 \mathrm{~h}$, for 4096 samples with an interval of $5 \mathrm{~s}$, from 15:00 h on February 28. The predominant period is around 60 min or shorter at GB807, GB804, GB802, GB801, GB811, and GB813; and it is longer than $60 \mathrm{~min}$ at the other buoys.

\section{Shallow-water Transformation between GPS Buoy and Coastal Tide Gauge Site}

There are five geometrically adjacent sets of a GPS buoy, coastal wave gauge, and coastal tide gauge on the Tohoku and Shikoku region coast. The tsunami profiles acquired at these sets are useful to discuss on tsunami propagation and transformation in shallow-water areas. Fig. 7 (a) shows the location of GPS buoy WG219, coastal wave gauge GB807, and coastal tide gauge TG219 in Kuji Port and the time series of the tide anomaly at these sites. The crests and troughs of the tide anomaly at GB807 corresponded well with those at WG219. The oscillation with a period of approximately $15 \mathrm{~min}$ at TG219 was significantly amplified after the tsunami arrived. Fig. 7 (b) shows the location of GPS buoy GB802, coastal wave gauge WG204, and coastal tide gauge TG204 in Kamaishi Port and the time series of the tide anomaly at these sites. The TG204 facility belongs to the Japan Coast Guard, and the data are transmitted to its system and to NOWPHAS. The tsunami crests and troughs at these three sites corresponded well to each other until around 16:00 h. A short period oscillation was significantly amplified at TG204. The frequency spectra will be compared later among the three sites of these two geometrically adjacent sets, together with the case of the 2011 Tohoku Foreshock Tsunami.

Fig. 8 shows the first crest height $Z_{1}$, the highest crest height $Z_{H}$, and the lowest trough depth $Z_{L}$, at the five geometrically adjacent sets of a GPS buoy, coastal wave gauge, and coastal tide gauge. The four sets, which include GPS buoys GB805, GB807, GB802, and GB801, are located off the Tohoku region coast, while the other set, which includes GB814, is located off the Shikoku region coast. The tsunami provided the first opportunity to study the variations in these parameters with water depth. The absolute values of these quantities are less than $0.3 \mathrm{~m}$ at the water depth of the GPS buoys, quickly increase in the range of the coastal wave gauges, and then reach much larger values at the coastal tide

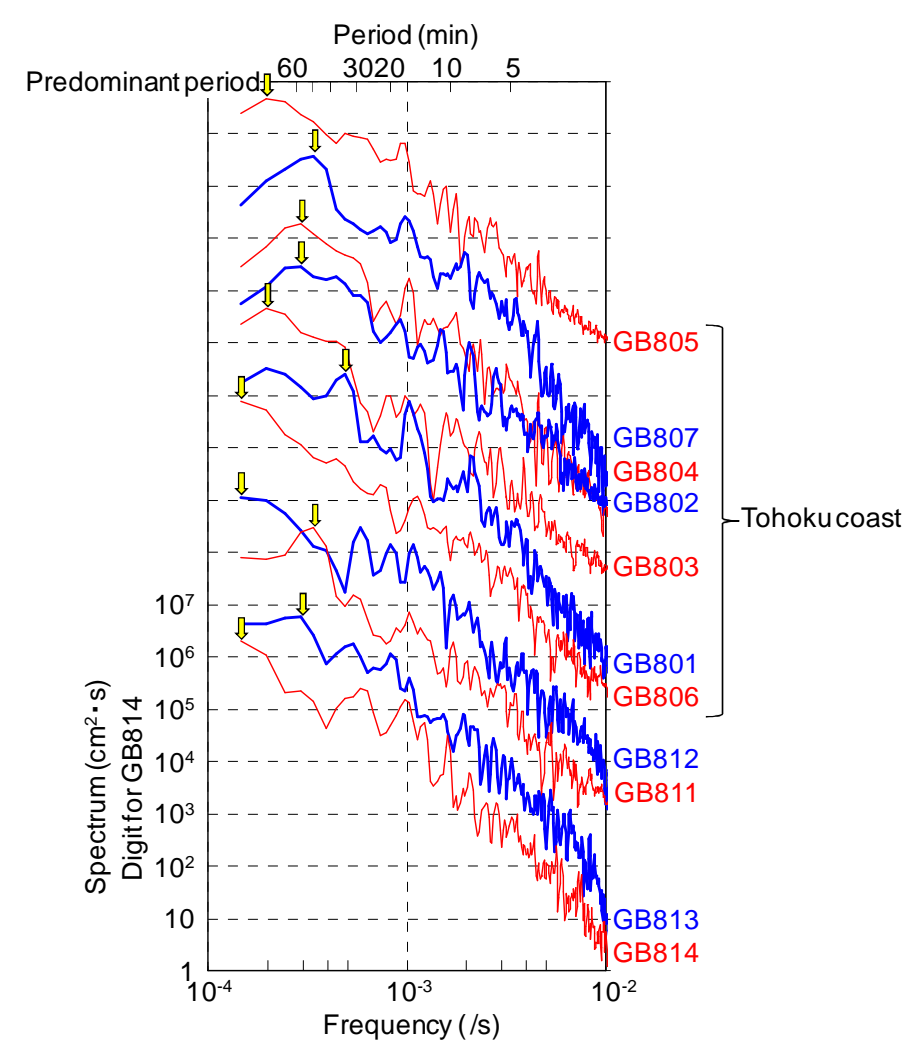

Figure 6. The 2010 Chilean Tsunami frequency spectra obtained by GPS buoys 

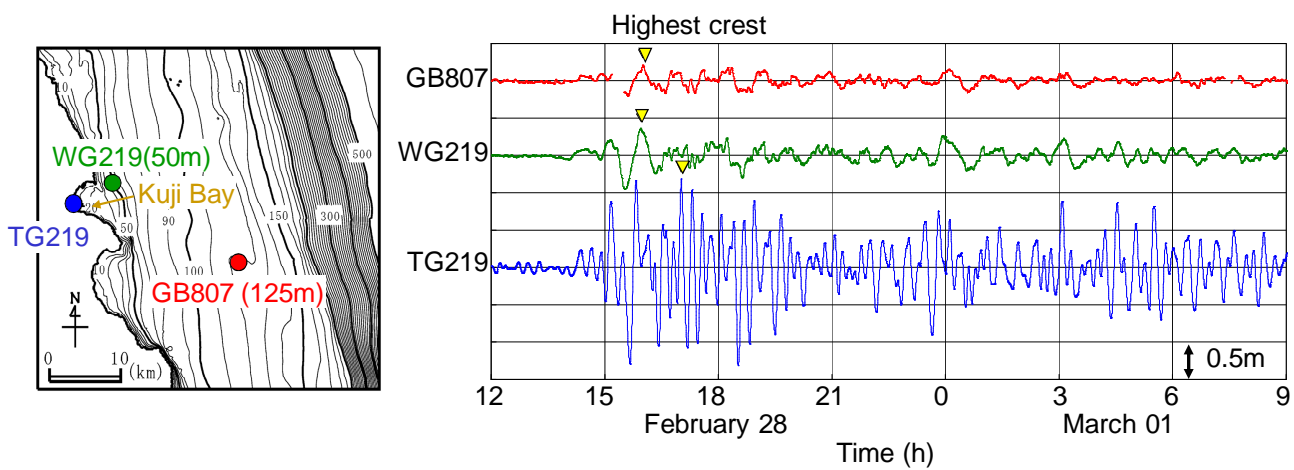

(a) In and off Kuji Port
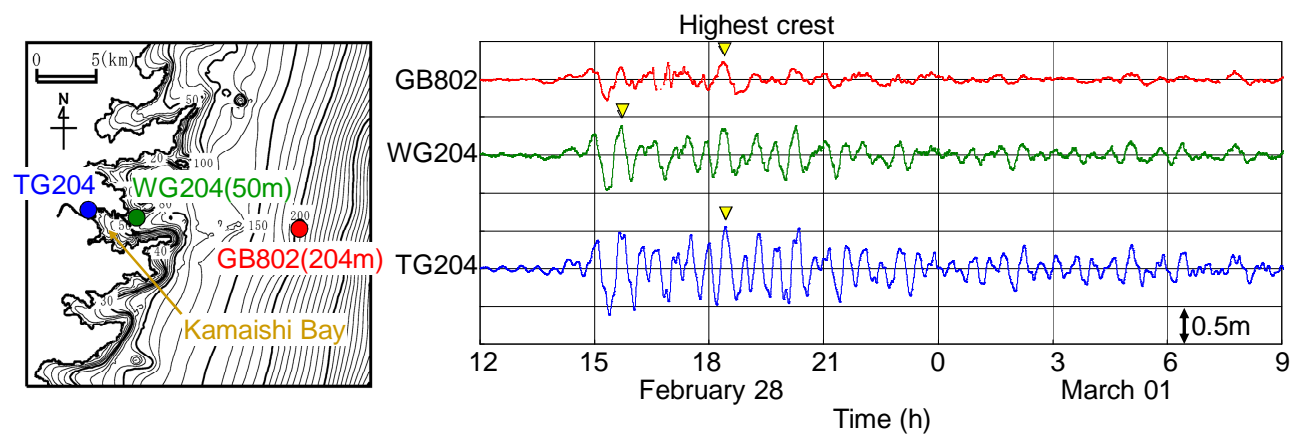

(b) In and off Kamaishi Port

Figure 7. The 2010 Chilean Tsunami profile acquired by geometrically adjacent sets of a GPS buoy, coastal wave gauge, and coastal tide gauge on the Tohoku region coast

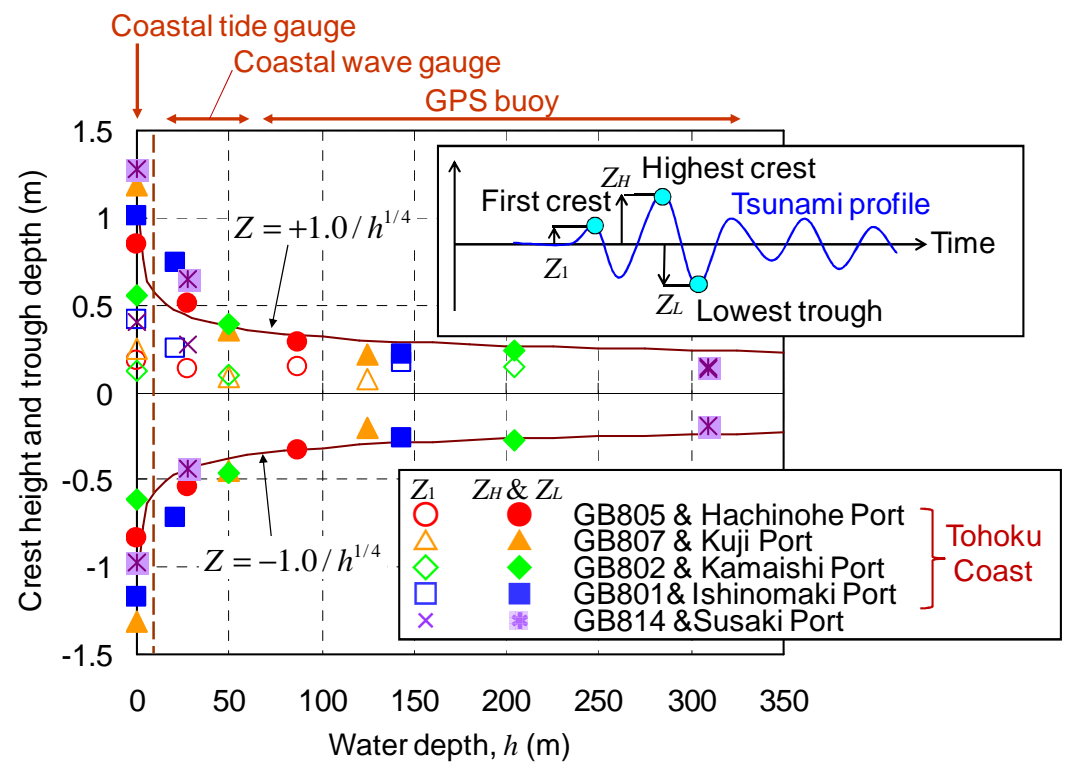

Figure 8. Variation of the first and highest crest heights and lowest trough depth with water depth

gauges. According to Green's law based on energy flux conservation and assuming no wave breaking, the tsunami wave height is inversely proportional to the $1 / 4$ power of the water depth and to the $1 / 2$ power of the bay width or wave path interval. In the range of the GPS buoys and coastal wave gauges, the plots for $Z_{H}$ and $Z_{L}$ are distributed near the equations $Z=+1.0 / h^{1 / 4}$ and $Z=-1.0 / h^{1 / 4}$, respectively, where $h$ is the water depth and $Z$ is the crest height or trough depth. One reason why the plots for the five sets are near the curved lines may be that the deep-water tsunami wave height was almost constant spatially off the Japanese coast owing to its large distance from Chile. On the other hand, those plots for 
the coastal tide gauge sites are scattered widely from the curved lines because the coastal tide gauges are located in bays of various shape, length, and water depth. The breakwater at the bay mouth reduces the tsunami height entering the bay.

A tsunami travelling time is a quite useful parameter for coastal disaster prevention works, such as gate operation and evacuation. However, it is difficult to determine the precise arrival time of a feeble tsunami wave on a tide anomaly profile including harbor oscillations and GPS positioning errors. This study, therefore, determined the first zero-up-crossing time rather than the tsunami arrival time. This is a similar approach to previous studies (Nagai et al. 2004, 2005a, 2006b; Shimizu et al. 2007). Fig. 9 compares the first zero-up-crossing time $t_{1}$ and the highest crest time $t_{H}$ among GPS buoys, seabed wave gauges, and coastal tide gauges. The difference in the first zero-up-crossing time between the GPS buoys and coastal wave gauges is 4-34 min and that between the coastal wave and tide gauges is less than 4-5 min. The highest crest time does not necessarily follow the order of a GPS buoy, coastal wave gauge, and coastal tide gauge.

\section{THE 2011 TOHOKU FORESHOCK TSUNAMI}

\section{Tsunami Profile Acquired by GPS Buoys}

According to JMA's analysis, the 2011 Tohoku Foreshock $\left(M_{w}=7.2\right)$ occurred off the Pacific coast of Tohoku region at 11:45 h, March 09, 2011, that was one day and $21 \mathrm{~h}$ before the main shock. Fig. 10 shows the location of the epicenter and the tide anomaly profiles, which were acquired by the GPS buoys using the same filter as the case of the 2011 Chilean Tsunami. The tsunami arrived at GPS buoys

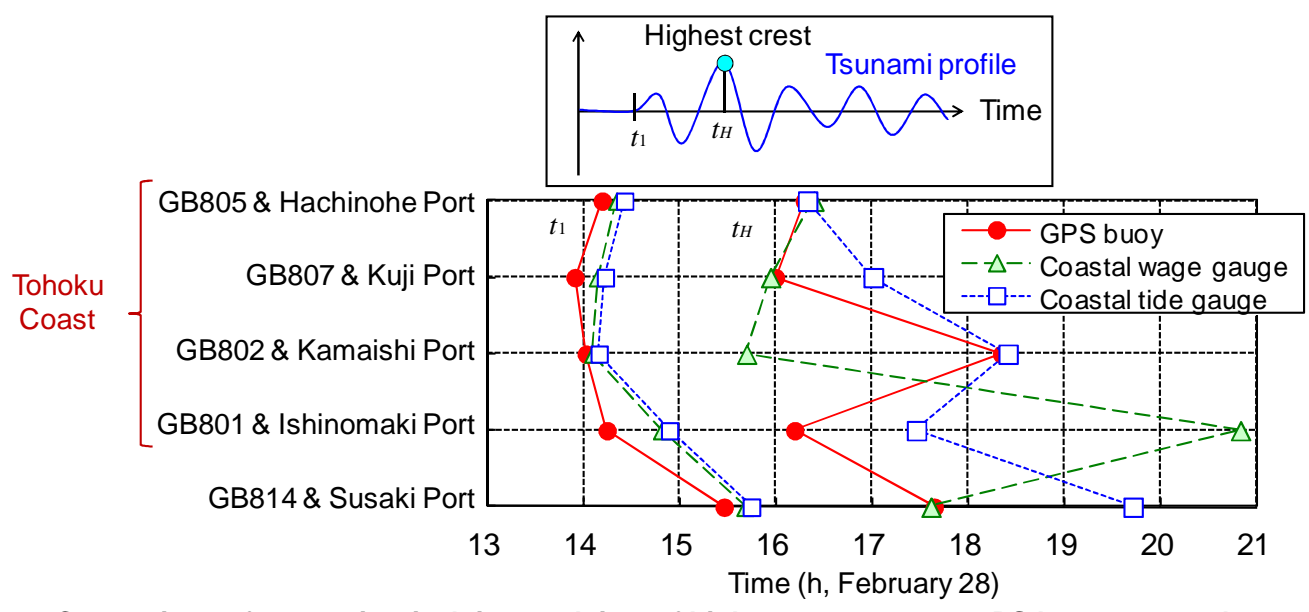

Figure 9. Comparison of tsunami arrival time and time of highest crest among GPS buoys, coastal wave gauges and coastal tide gauges
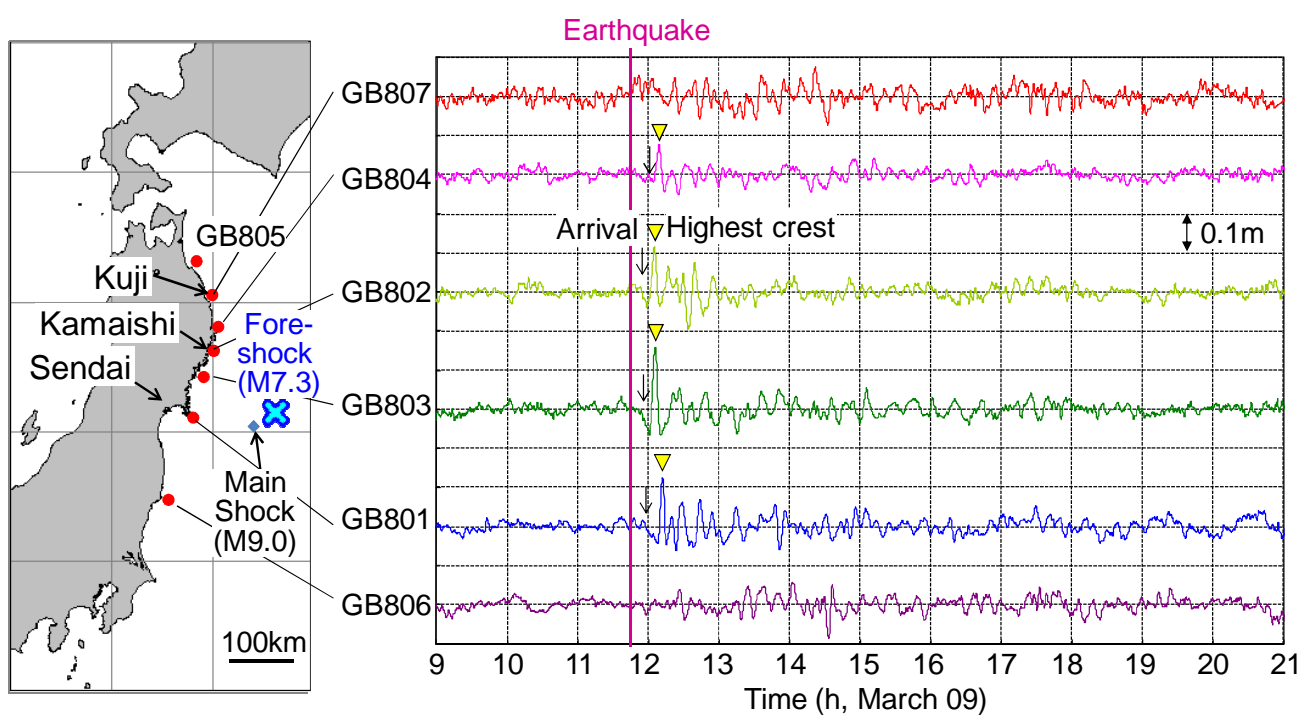

Figure 10. The 2011 Tohoku Foreshock Tsunami profile acquired by GPS buoys off the Tohoku region coast 
GB804, GB802, GB803, and GB801 between 11:56 and 12:01 h, those were 11 and 16 min, respectively, after the earthquake occurred, and then the first crest reached the highest level in the entire tsunami event between 12:06 and 12:10 h. The tsunami wave periods were 10-20 min, which was much shorter than the 2010 Chilean and 2011 Tohoku Main Shock Tsunami. On the other hand, it is difficult to determine the tsunami arrival time at GB807 and GB806 owing to small amplitudes of the tsunami signals.

\section{Shallow-water Transformation between GPS Buoy and Coastal Tide Gauge Site}

Fig. 11 shows the time series of the tide anomaly at two geometrically adjacent sets of a GPS buoy, coastal wave gauge, and coastal tide gauges on the Tohoku region coast, which are the same sets as those shown in Fig. 7. The tsunami signals were too feeble to determine the time of the tsunami arrival and highest crest at GPS buoy GB807 off Kuji Bay, while it can be easily confirmed that the third crest was highest at coastal tide gauge TG219. The bay resonance continued for a long time more than $18 \mathrm{~h}$, which is presented in the figure. The tsunami signals at GB802 off Kamaishi Bay were distincter than those at GB807. One of the reasons may be a shorter distance from the epicenter. The first crest was highest during the entire tsunami event at three sites GB802, WG204, and TG204.

Fig. 12 shows the frequency spectra of the 2010 Chilean and 2011 Tohoku Foreshock Tsunami at the GPS buoy, coastal wave gauge, and coastal tide gauge as well as the amplification ratio for the major tsunamis in 2003 and later. In the frequency spectra of the 2010 Chilean and 2011 Tohoku Foreshock Tsunami profile at coastal tide gauge TG219 in Kuji Port, a distinct predominant period can be found near 23, 15, and $10 \mathrm{~min}$. These periods are within or near the range of a high amplification ratio between 8 and $16 \mathrm{~min}$, which were obtained in the 2003 Tokachi-oki Earthquake Tsunami and the 2005 Miyagi-ken-oki Earthquake Tsunami (Nagai et al., 2004, 2005a, 2006b). In the frequency spectra at coastal tide gauge TG204 in Kamaishi Bay, a distinct predominant period can be found near 27 and $10 \mathrm{~min}$. These periods are also within or near the range between 5 and $18 \mathrm{~min}$ in the 2003 Tokachi-oki Earthquake Tsunami, the 2005 Miyagi-ken-oki Earthquake Tsunami, and the 2006 Kuril Islands Earthquake Tsunami (Shimizu et al., 2007). These predominant periods at these coastal tide gauges are attributed to the natural oscillation frequency in these bays and their connecting sea bodies.
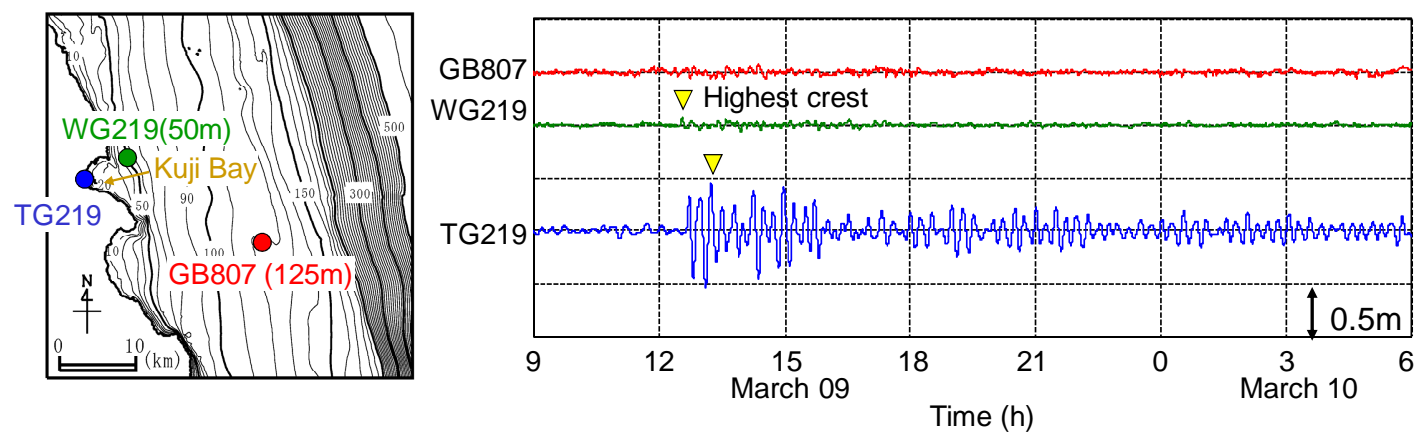

(a) In and off Kuji Port
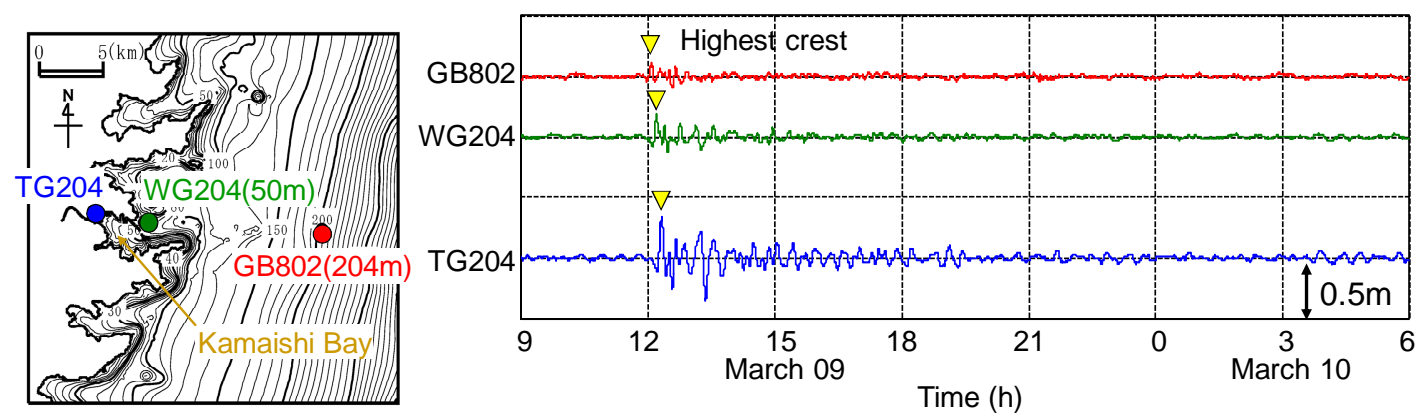

(b) In and off Kamaishi Port

Figure 11. The 2011 Tohoku Foreshock Tsunami profile acquired by geometrically adjacent sets of a GPS buoy, coastal wave gauge, and coastal tide gauge on the Tohoku region coast 

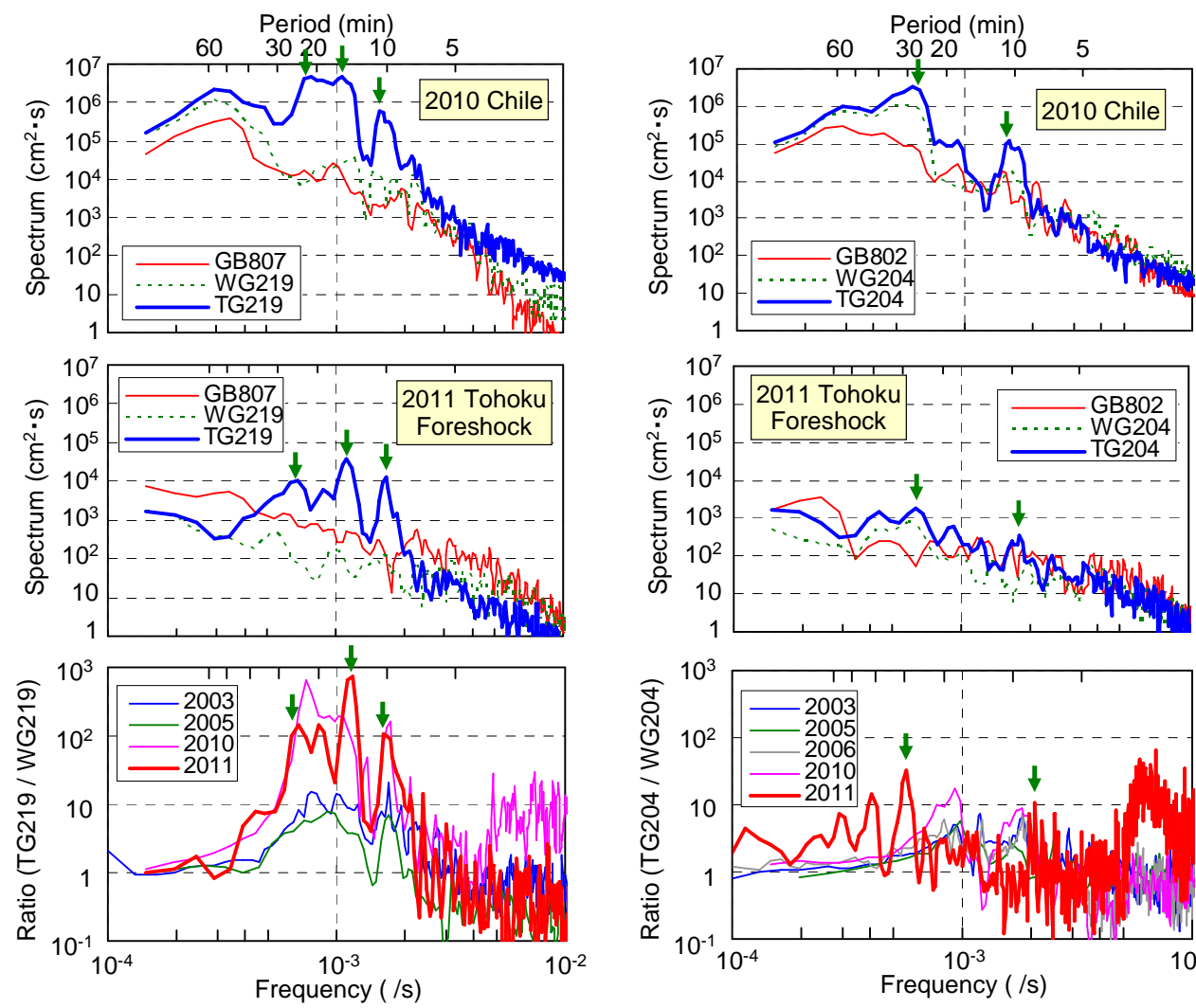

(a) In and around Kuji Port

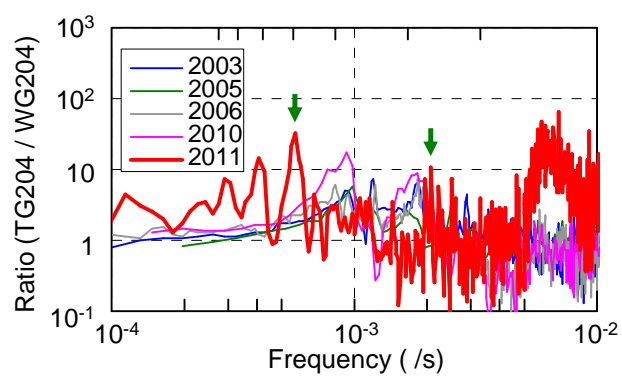

(b) In and around Kamaishi Port

Figure 12. The 2010 Chilean and 2011 Tohoku Foreshock Tsunami frequency spectra and amplification ratio

\section{THE 2011 TOHOKU MAIN SHOCK TSUNAMI}

\section{Earthquake and Wave Condition}

According to JMA's analysis, the 2011 Tohoku Main Shock $\left(M_{w}=9.0\right)$ occurred near the epicenter of the foreshock off the Pacific coast of Tohoku region at 14:46, March 11, 2011, as shown in Fig. 10. Its tsunami height exceeded $6 \mathrm{~m}$ at the GPS buoy at a spot of $204 \mathrm{~m}$ in water depth off Kamaishi Port and reached 10-20 m on the shore. Long breakwaters, seawalls, and coastal dikes were destroyed and wide rearward land areas were flooded on the Pacific coast from the Hokkaido to Kanto region (Mori et al., 2011, 2012; PARI, 2011). On the day that the tsunami was triggered, low-pressure systems covered the northern part of Japan and wind blew toward SE on the Pacific coast of Tohoku region. The significant wave height and period at the GPS buoy off Kamaishi Port was only $0.73 \mathrm{~m}$ and $6.8 \mathrm{~s}$, respectively, at 14:40 h. Such a calm wave condition is advantageous to the extraction of the tsunami signals from the time series of the water surface elevation.

\section{Overview of Tsunami Profile Acquired by GPS Buoys}

Fig. 13 shows the time series of the tide anomaly acquired by all the GPS buoys off the Tohoku to Sikoku region coast. The astronomical tide level included in the tidal level was estimated with the known tide constituents. Only at GB812, the data on the buoy tilting angle included irregular noises, which gave unrealistic tsunami profile; therefore the buoy altitude was not corrected using the tilting angle in this paper. It does not cause a critical problem, because the wave condition was calm and the wave components can be easily averaged using the digital filter. The tsunami signals began with a 0.2 $0.5 \mathrm{~m}$ deep trough and the subsequent crest was highest during the entire record at 5 GPS buoys between GB807 and GB801 off the Tohoku region coast, while the second crest was highest at GB806. These highest crests appeared between 15:12 and 15:19 h, approximately half hour after the earthquake occurred, and the appearance time was earliest at GB804 and GB802. The crest height ranged between 2.6 and $6.7 \mathrm{~m}$ above the mean tide anomaly before the earthquake, and was highest at GB802 off Kamaishi Port. The lowest trough depth was $5.1 \mathrm{~m}$ at GB801. There were 7 major waves at GB802. The crest height of the first wave was much larger than that of the subsequent ones and the period was 


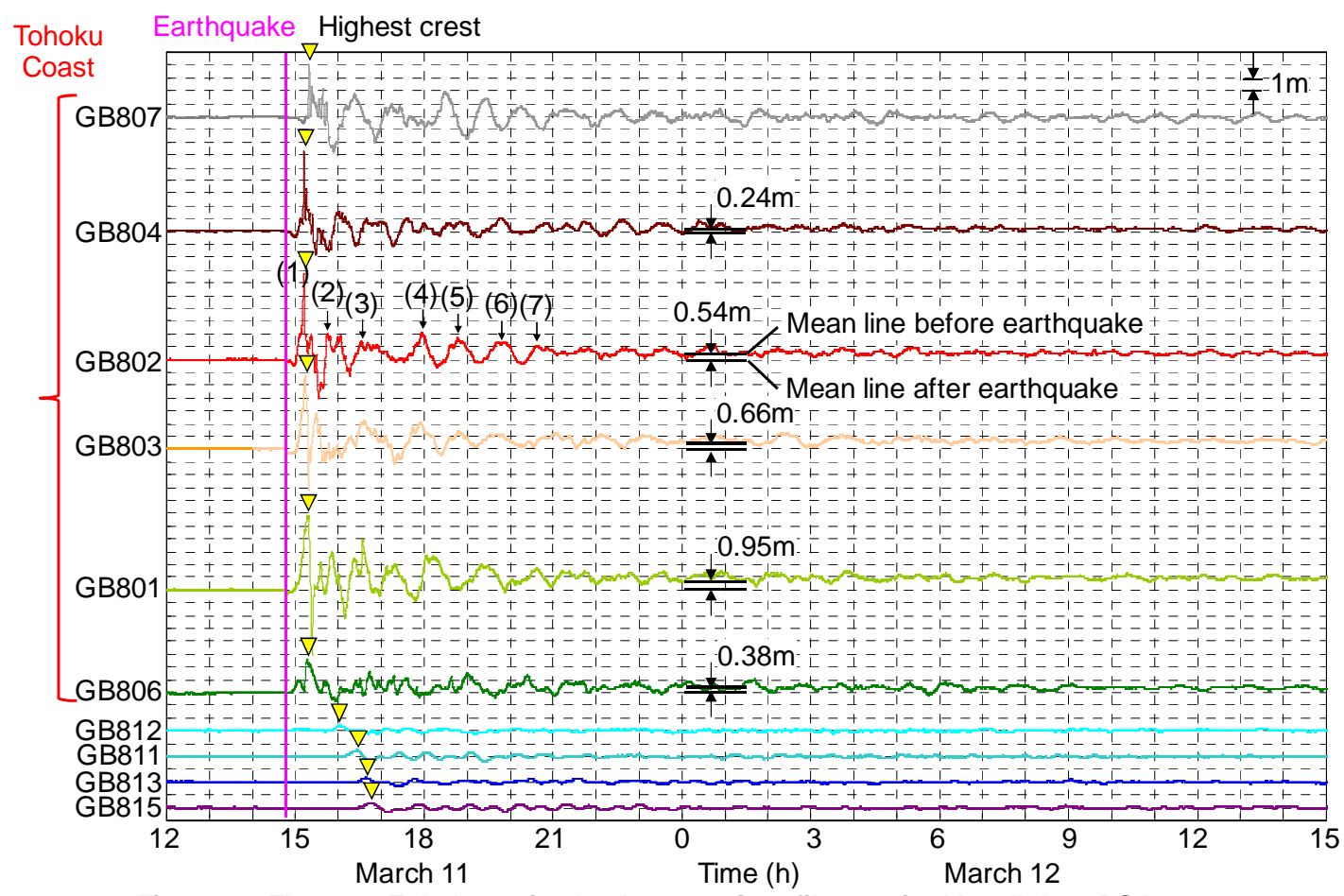

Figure 13. The 2011 Tohoku main shock tsunami profile acquired by all the GPS buoys

not constant from the first to third wave. The crest height gradually decreased and the period was almost constant near $50 \mathrm{~min}$, from the fourth to seventh wave. Similar characteristics can be found at GB807, GB804, GB803, and GB801.

Fig. 13 shows that the mean tide anomaly line after the earthquake looks higher than that before the earthquake at 5 GPS buoys between GB804 and GB806 in South Tohoku region. The variation in the mean tide anomaly is estimated between 0.24 and $0.95 \mathrm{~m}$ at these sites and is largest at GB801. The GPS buoy system on NOWPHAS observes the relative altitude of the buoy from the base station and then adds the absolute altitude of the base station which was measured at the time of installation. The variation in the mean tide anomaly line, therefore, was owing to the subsidence of the base station. In reality, according to the vertical displacement of the GEONET GPS stations (Nishimura et al., 2011), a large-scale land subsidence occurred in northeast Japan, principally in South Tohoku region by the main shock and the subsequent aftershocks, and the maximum subsidence of $1.20 \mathrm{~m}$ was recorded at Oshika. Among these 5 GPS buoys, GB801 is located nearest from Oshika. Even if the subsidence effect is removed from the observed tide anomaly, the crest height remains 2.1-6.1 $\mathrm{m}$ at 6 GPS between GB807 and GB806 off the Tohoku region coast.

The tsunami reached 4 GPS buoys GB812, GB811, GB813, and GB815 off the Chubu to Shikoku region coast, in the order of the increasing distance from the epicenter. The height of the first crest was 0.3-0.5 $\mathrm{m}$ and was slightly higher than that of the subsequent ones. The appearance time of the first crest was between 16:01 and 16:43 h, which is more than $1 \mathrm{hr}$ later than the earthquake occurrence.

\section{First Crest on Tsunami Profile Acquired by GPS Buoys on Tohoku Region Coast}

Fig. 14 magnifies the tsunami profiles near the tsunami arrival time at all the GPS buoys off the Tohoku region coast. The data on the left side of the dotted line were transmitted in real-time from the observation sites to the central data processing center in PARI and then were transferred to JMA. The tsunami profiles were displayed on the Real-time NOWPHAS Web. The data covered the highest crest at GB804, GB802, and GB803. However, some of the equipment were damaged by the intense seismic vibration and the massive tsunami flow and the data communication was cut off owing to congestion of the line and black out, in Tohoku region. Engineers, therefore, visited the base stations to take out the data disks and then connected the data in the disks with the data processed in real-time.

At GPS buoy GB802, which is located off Kamaishi Port, the tsunami anomaly increased by about $2 \mathrm{~m}$ within $6 \mathrm{~min}$ from 15:01 $\mathrm{h}$ and then increased more quickly by more than $4 \mathrm{~m}$ in the subsequent 4 min. Such a two-step rise can be found at not only GB802, but also GB807, GB804, GB803, and 


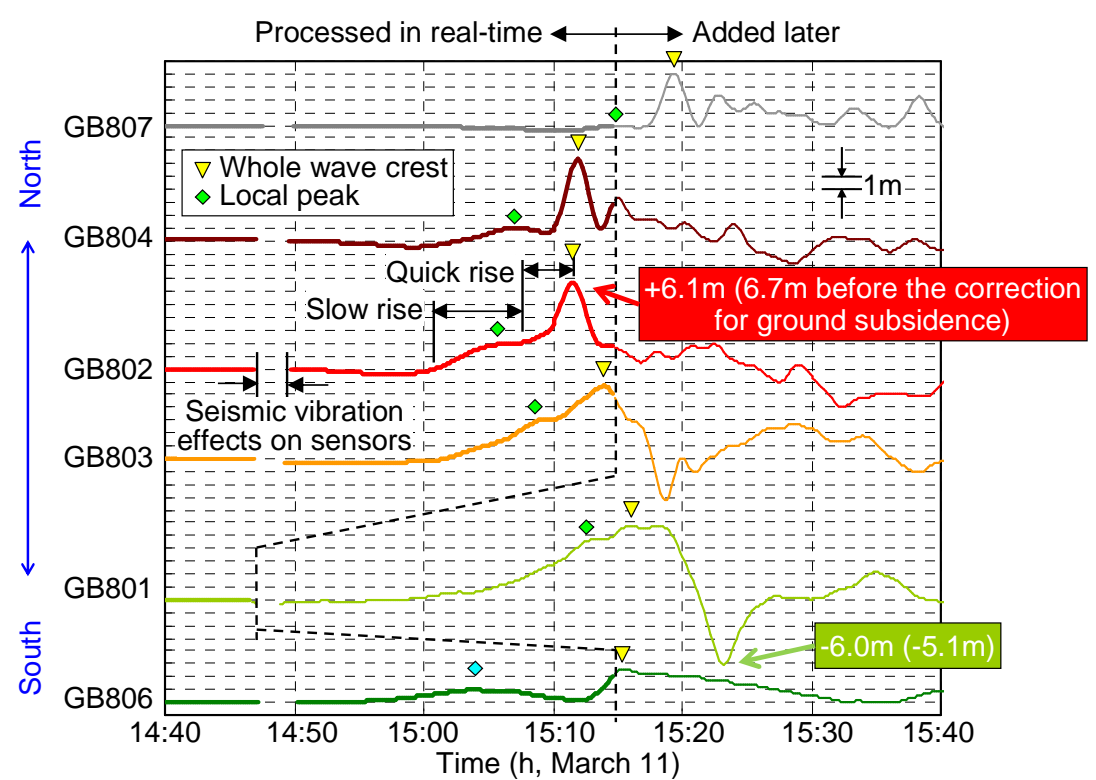

Figure 14. Detailed profile of the first wave of the 2011 Tohoku main shock tsunami off Tohoku region coast

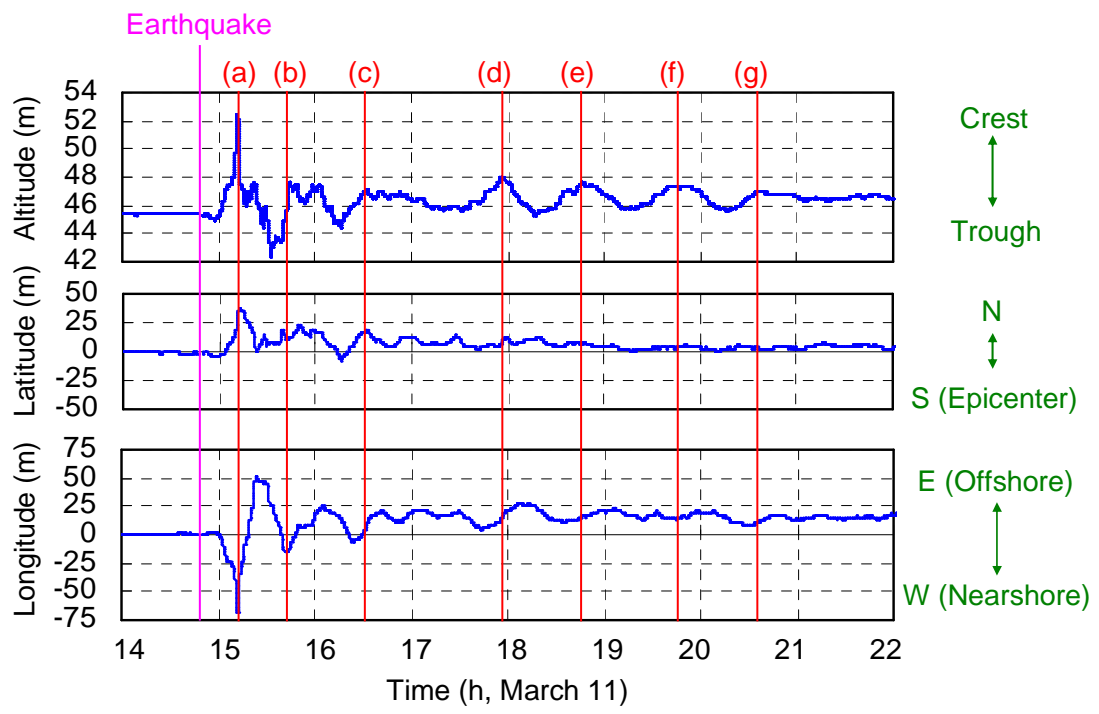

Figure 15. Time series of the buoy position at GB802 off Kamaishi Port

GB801. The ratio of the local peak height to the whole wave crest height is smaller than half at GB807, GB804, and GB802 on the northern side and is larger than half at GB803 and GB801 on the southern side. The time and magnitude of the two-step rise and the variation in the crest height ratio with the latitude are critical for the identification of the multiple tsunami source area.

\section{Tsunami Flow off the Tohoku Region Coast}

The length of the mooring chain of a GPS buoy is 2-3 times as long as the water depth as shown in Fig. 1. A part of the chain hangs down from the buoy and the other part lies on the sea bottom near the anchor. The buoy can drift due to the tsunami flow as well as the daily astronomical tide and ocean currents. The horizontal motion of the buoy is different from the horizontal excursion of the water particle in a tsunami because the behavior of the buoy relies on its inertial force and the tension of the mooring chain. But the drifting direction may give the tsunami flow direction.

Fig. 15 shows the time series of the 2-min-averaged three-dimensional position of GPS buoy GB802 off Kamaishi Port. The altitude in the figure is based on the Earth ellipsoid and includes the astronomical tide. The crests on the smoothed altitude profile appear almost simultaneously with those on the tide anomaly profile, because the change in the astronomical tide level during a tsunami crest is much smaller than the crest height. The latitudinal and longitudinal location in the figure is defined so 

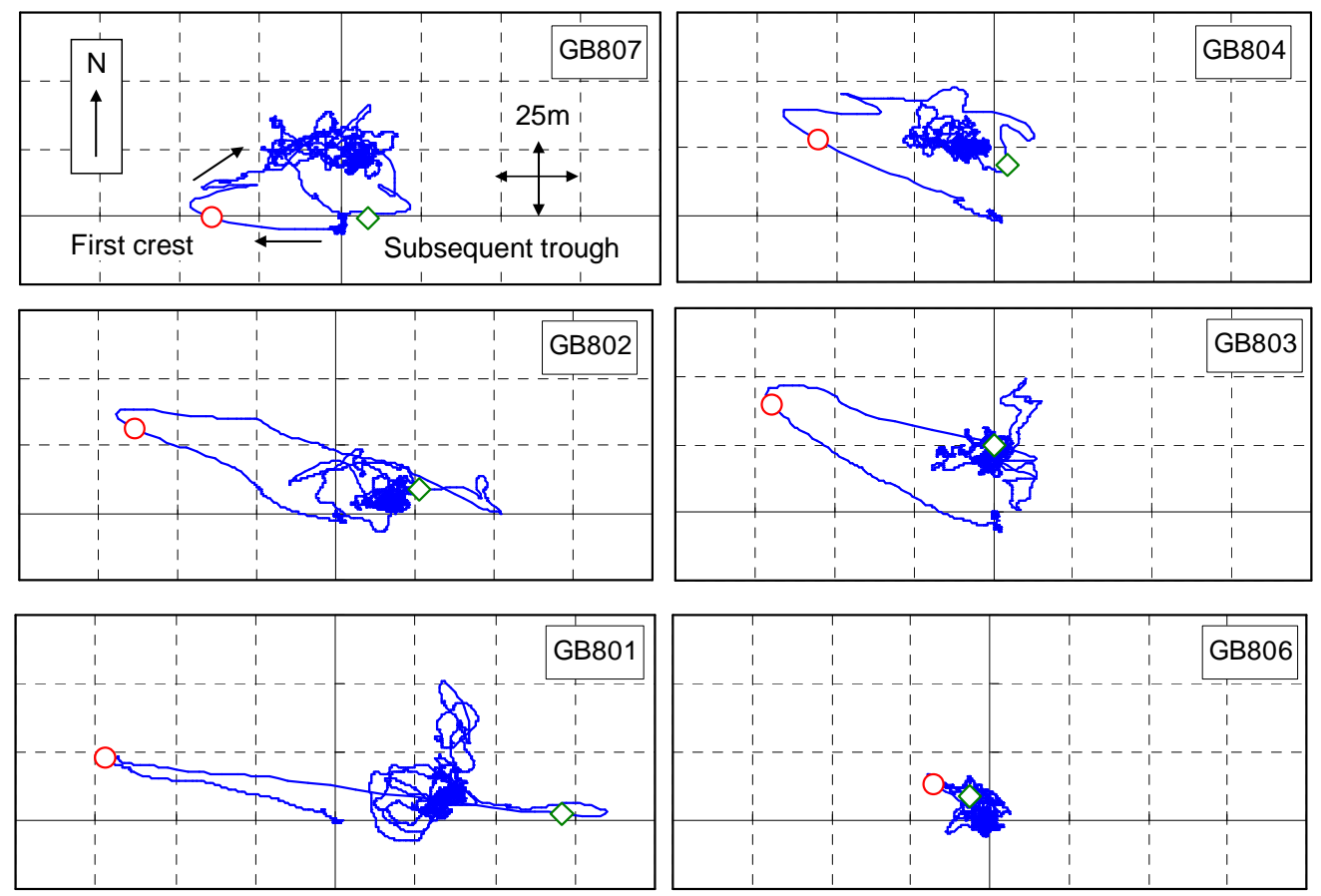

Figure 16. Trace of the buoy motion in a horizontal plane off the Tohoku region coast

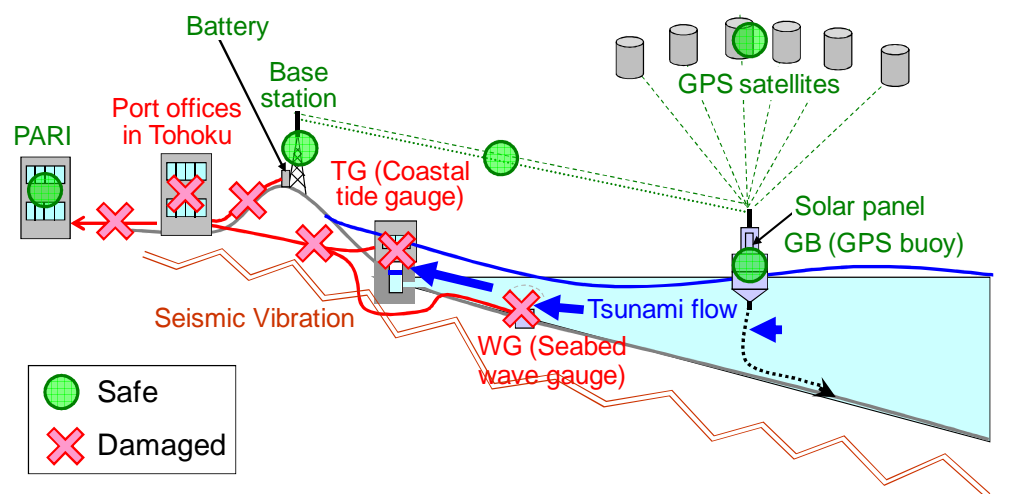

Figure 17. Seismic vibration and tsunami flow effects on NOPWHAS equipment on the Tohoku region coast

that the value is zero at 14:00 $\mathrm{h}$ before the earthquake occurred. The coastal line and the water depth counter lines run from NNE to SSW around the GPS buoy, as shown in Figs. 7(b) and 11(b). The earthquake epicenter is located toward SSE, as shown in Fig. 10. The buoy drifted toward N and W by about 31 and $63 \mathrm{~m}$, respectively, when the altitude reached the first crest (a). The crests in the altitude, the northern peaks in latitude, and the western peaks in longitude corresponded well to each other until the third crest (c) and peaks.

Fig. 16 shows the trace of the buoy position in a horizontal plane, during the same period as Fig. 15, of all the GPS buoys off the Tohoku region coast. The circles and diamonds in the figure indicate the positions at the time of the first crest and the subsequent trough, respectively, on the altitude profile. GPS buoys GB807, GB804, GB802, GB803, and GB801 drifted toward W or WNW when the altitude reached the first crest. GPS buoy GB806 drifted toward NW, but the distance is within the range of the normal drifting due to the daily astronomical tide and ocean currents. GB807, GB804, GB802, and GB803 returned near their original positions and GB801 reached near the opposite position, when the altitude reached the subsequent trough.

\section{Shallow-water Tsunami Transformation}

On the Pacific coast of Tohoku region, there are several geometrically adjacent sets of a GPS buoy, seabed wave gauge, and coastal tide gauge. These sets are convenient for the evaluation of the tsunami 


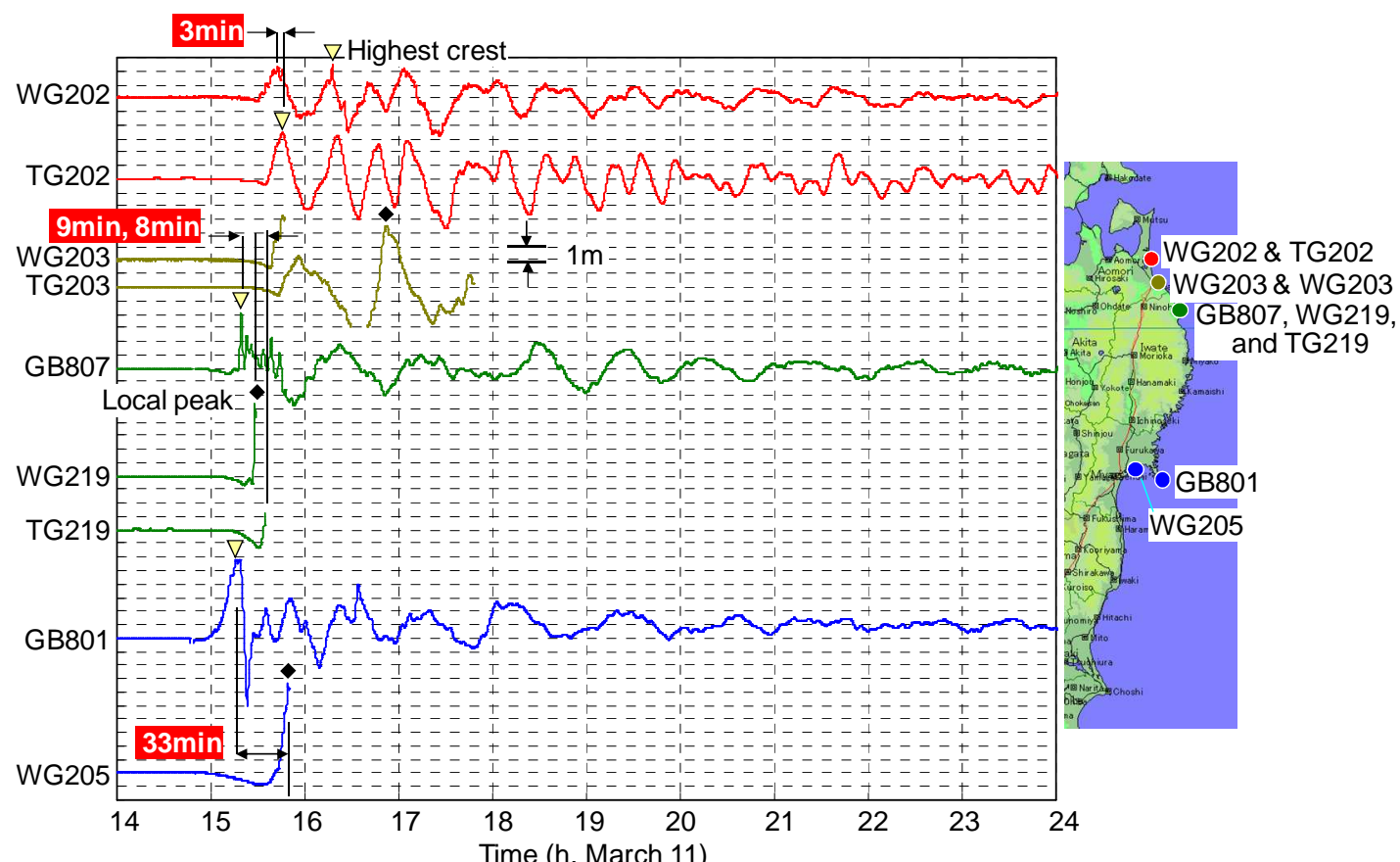

Figure 18. The 2011 Tohoku Main Shock Tsunami profile acquired by geometrically adjacent sets of a GPS buoy, coastal wave gauge and coastal tide gauge on the Tohoku region coast

propagation time and the shallow-water amplification ratio as mentioned in the analysis on the 2010 Chilean and 2011 Tohoku Foreshock Tsunami. Unfortunately, most of the coastal wave and tide gauges on the coast were affected by the 2011 Tohoku Main Shock and its tsunami, as illustrated in Fig. 17. The limited sets shown in Fig. 18, namely WG202-TG202, WG203-TG203, GB807-WG219-TG219, and GB801-WG205, are consequently available.

In Mutsu-Ogawara Port, the tsunami profile could be acquired by coastal wave gauge WG202 and coastal tide gauge TG202. The tsunami profile began with a trough at these sites. The first crest appeared at WG202 earlier than at TG202. The first to fourth crests at TG202 corresponded well with those arriving at WG202. Short period components appeared significantly at TG202 from the fifth wave.

In Hachinohe Port, coastal wave gauge WG203 detected the tsunami arrival and coastal tide gauge TG203 recorded two crests, while GPS buoy GB805 was undergoing repairs. The tsunami recorded at TG203 was discontinuous from 16:29 to $16: 39 \mathrm{~h}$ because the water level fell below the range of measurement, but it shows that the tide anomaly fell to $-3.0 \mathrm{~m}$ or below and then rose to a $4.6 \mathrm{~m}$ high crest. A survey of high water marks on land in the port area, which was protected by the breakwater, revealed an inundation height of 5.4-6.4 $\mathrm{m}$ above the astronomical tide level (PARI, 2011).

Kuji Port is monitored by GPS buoy GB807, coastal wave gauge WG219, and coastal tide gauge TG219. At these sites, the record shows the tsunami profile began with a trough. The time of the lowest tide anomaly in the trough was recorded earliest at GB807, while the largest trough depth was recorded at TG219. The time differences between GB807 and WG219, and between WG219 and TG219, were 11 and 9 min, respectively. GB807 recorded a $4.0 \mathrm{~m}$ high first crest at 15:19 h, WG219 recorded a 5.4 $\mathrm{m}$ high first crest or local peak at 15:28 h, and TG219 recorded that the tide anomaly increased until 15:36 $\mathrm{h}$ or later. It shows the tsunami crest propagating time is 9 min or longer between GB807 and WG219 and 8 min or longer between WG219 and TG219, as indicated in the figure. The survey of high water marks on land in the port area showed an inundation height of 8.2-8.5 m above the astronomical tide level (PARI, 2011).

There are GPS buoy GB801 off the Oshika Peninsula and coastal wave gauge WG205 near the entrance of Sendai-Shiogama Port. The tsunami profile began to rise before 15:00 $\mathrm{h}$ and the first crest passed at 15:16 at GB801, while it began with a $0.9 \mathrm{~m}$ deep trough at $15: 31 \mathrm{~h}$ and then rose quickly to a $6.7 \mathrm{~m}$ high first crest or local peak at 15:49 h at WG205. Unfortunately, the precise effect of the crustal movement on the tsunami profile recorded at WG205 is unknown. The onshore current velocity reached $3.2 \mathrm{~m} / \mathrm{s}$ at WG205. The survey of high water marks on land in the port area showed an inundation height of 7.3-8.0 m (PARI, 2011). 

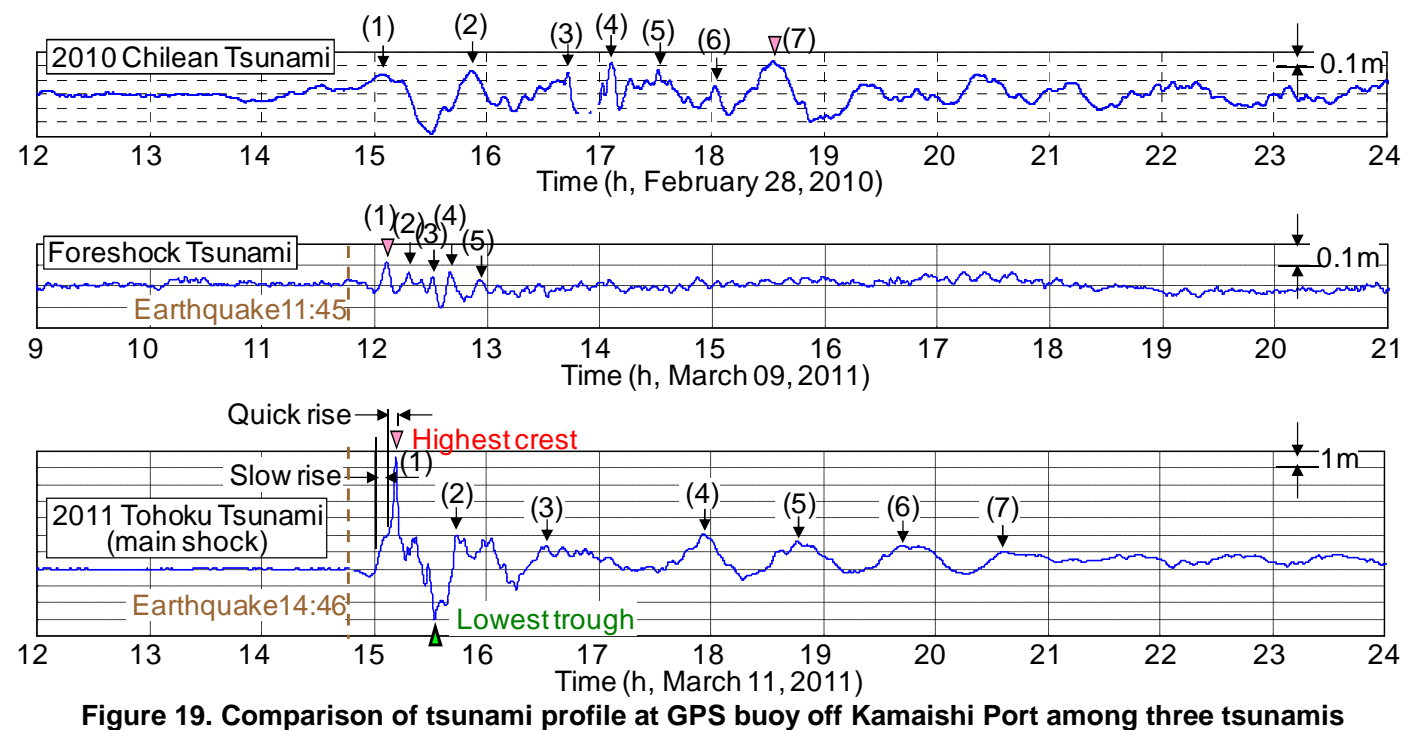

\section{COMPARISON OF THREE TSUNAMIS}

Fig. 19 compares the 2010 Chilean and 2011 Tohoku Foreshock and Main Shock Tsunami profiles, which were acquired by GPS Buoy GB802 off Kamaishi Port. The magnitude of the 2011 Tohoku Foreshock $\left(M_{w}=7.2\right)$ is much smaller than that of the main shock $\left(M_{w}=9.0\right)$, therefore the amplitude, period and duration of the foreshock tsunami is respectively smaller than that of the main shock tsunami. Only the similarity between these tsunamis is that the first crest was higher than the second and subsequent owing to a short travelling distance from the tsunami source. The magnitude of the 2010 Chilean Earthquake $\left(M_{w}=8.8\right)$ is near that of the 2011 Tohoku Main Shock $\left(M_{w}=9.0\right)$, therefore these tsunami periods were long around $1 \mathrm{~h}$. The amplitude of the 2010 Chilean Tsunami is much less than that of the 2011 Tohoku Main Shock Tsunami and the seventh crest was highest on the Japanese coast, owing to a long travelling distance from Chile.

\section{CONCLUDING REMARKS}

This paper introduced the GPS buoy system on NOWPHAS and then described the overview of the 2010 Chilean and 2011 Tohoku Foreshock and Main Shock Tsunami profiles. The following things were found through the observations.

- The GPS buoy system could extract tsunami signals at a spot of 100-400 $\mathrm{m}$ in water depth even if the amplitudes are a few ten centimeters. The system is useful for early tsunami detection.

- A geometrically adjacent set of a GPS buoy, coastal wave gauge, and coastal tide gauge could determine the tsunami propagation time and amplification ratio in the shallow-water area as well as the predominant periods in the bay oscillations. Such fundamental data are useful for the calibration of numerical models and the tsunami risk assessment in the coastal area.

- In the case of the 2011 Tohoku Main Shock Tsunami, the GPS buoy off Kamaishi Port recorded the first crest higher than $6 \mathrm{~m}$ with a two-step rise. Such a unique shape of the crest can be critical for the determination of the spatially and temporary characteristics of the tsunami genesis due to a mega earthquake.

\section{ACKNOWLEDGMENTS}

This paper used data obtained through NOWPHAS, operated by the Ports and Harbours Bureau, Ministry of Land, Infrastructure, Transport and Tourism, Japan, and its associated organizations. The TG204 facility belongs to Japan Coast Guard. We would like to express our gratitude to all the abovementioned organizations for their cooperation.

\section{REFERENCES}

Kato, T., Y. Terada, K. Ito, R. Hattori, T. Abe, T. Miyake, S. Koshimura, and T. Nagai. 2005. Tsunami due to the 5 September 2004 off the Kii Peninsula Earthquake, Japan, recorded by a new GPS buoy," Earth Planets Space, 57, 297-301. 
Kawai, H., M. Satoh, M. Miyata, and T. Kobayashi. 2011. The 2010 Chilean Tsunami observed by GPS buoys, seabed wave gauges and coastal tide gauges of NOWPHAS, Proceedings of $21^{\text {st }}$ International Offshore and Polar Engineering Conference, ISOPE, 3, 266-270.

Kawai, H., M. Satoh, K. Kawaguchi, and K. Seki. 2012. The 2011 off the Pacific Coast of Tohoku Earthquake Tsunami Observed by the GPS Buoys, Seabed Wave Gauges, and Coastal Tide Gauges of NOWPHAS on the Japanese Coast, Proceedings of $22^{\text {nd }}$ International Offshore and Polar Engineering Conference, ISOPE, 3, 20-27.

Mori, N., T. Takahashi, T. Yasuda, and H. Yanagisawa. 2011. Survey of 2011 Tohoku Earthquake Tsunami inundation and run-up, Geophysical Research Letters, 38, L00G14, doi:10.1029/2011 GL049210.

Mori, N., Takahashi, T. \& the 2011 Tohoku Earthquake Tsunami Joint Survey Group. 2012. Nationwide Post Event Survey and Analysis of the 2011 Tohoku Earthquake Tsunami, Coastal Engineering Journal, Elsevier, 54-1, 1250001.

Nagai, T., H. Ogawa, K. Nukada, and M. Kudaka. 2004. Characteristics of the observed 2003 Tokachioff Earthquake Tsunami profile, Coastal Engineering Journal, JSCE, 51, 276-280 (in Japanese).

Nagai, T. and S. Satomi. 2005a. Records of observed 2004 Tokaido-off Earthquake Tsunami profile, Technical Note of the Port and Airport Research Institute, 1096 (in Japanese).

Nagai, T., S. Satomi, Y. Terada, T. Kato, K. Nukada, and M. Kudaka. 2005b. GPS buoy and seabed installed wave gauge application to offshore tsunami observation, Proceedings of $15^{\text {th }}$ (2005) International offshore and polar engineering conference, ISOPE, 3, 292-299.

Nagai, T., T. Kato, N. Moritani, H. Izumi, Y. Terada, and M. Mitsui. 2006a. Offshore tsunami monitoring network design using GPS buoys and coastal on-site sensors, Proceedings of 30th International Conference on Coastal Engineering, ASCE, 2, 1529-1540.

Nagai, T., and S. Satomi. 2006b. Records of the observed 2005 Miyagi-Prefecture-off Earthquake Tsunami profile, Technical Note of the Port and Airport Research Institute, 1119 (in Japanese).

Nagai, T., T. Kato, N. Moritani, H. Izumi, Y. Terada, and M. Mitsui. 2007. Proposal of hybrid tsunami monitoring network system consisted of offshore, coastal and on-site wave sensors, Coastal Engineering Journal, 49-1, 63-76.

Nagai, T., K. Shimizu, M. Sasaki, and M. Murakami. 2008. Improvement of the Japanese NOWPHAS network by introducing advanced GPS buoys, Proceedings of $18^{\text {th }}$ (2008) International Offshore and Polar Engineering Conference, 3, 558-564.

Nishimura, T., H. Munekane, and H. Yarai. 2011. The 2011 off the Pacific Coast of Tohoku Earthquake and its aftershocks", Earth Planets Space, 63, 631-636.

Port and Airport Research Institute. 2011. Executive summary of urgent field survey earthquake and tsunami disasters by the 2011 off the Pacific Coast of Tohoku Earthquake, available at http://www. pari.go.jp/en/files/items/3496/File/20110325.pdf

Shimizu, K., T. Nagai, J.H. Lee, H. Izumi, M. Iwasaki, and T. Fujita. 2006a. Development of real-time tsunami detection system using offshore water surface elevation data," Proceedings of TECHNOOCEAN 2006, JASNAOE, 24.

Shimizu, K., T. Nagai, S. Satomi, J.H. Lee, M. Kudaka, and T. Fujita. 2006b. Development of the deepsea GPS buoy wave data processing system, Proceedings of TECHNO-OCEAN 2006, Kobe, JASNAOE, 27.

Shimizu, K., M. Sasaki, and T. Nagai. 2007. Characteristic of the 2006 Chishima-Islands-off Earthquake Tsunami profile, Technical Note of Port and Airport Research Institute, 1162 (in Japanese).

Takayama, T., Y. Suzuki, H. Tsuruya, S. Takahashi, C. Gotoh, T. Nagai, N. Hashimoto, T. Nagao, T. Hosoyamada, K. Shimosako, K. Endo, and T. Asai. 1994. Field investigations of tsunami caused by 1993 Hokkaido Nansei-oki Earthquake, Technical Note of Port and Harbour Research Institute, 775 .

Tanimoto, K., T. Takayama, K. Murakami, S. Murata, H. Tsuruya, S. Takahashi, M. Morikawa, Y. Yoshimoto, S. Nakano, and T. Hiraishi. 1983. Field and laboratory investigations of the tsunami caused by 1983 Nihonkai Chubu Earthquake, Technical Note of Port and Harbour Research Institute, 470 (in Japanese). 